\title{
Superhard Coating Materials
}

\section{Yip-Wah Chung and William D. Sproul, Guest Editors}

\begin{abstract}
"Superhard" coating materials are defined by hardness values that exceed $40 \mathrm{GPa}$ In this issue of MRS Bulletin, we focus on noncarbon-based superhard coatings, with the exception of a review of carbon nitride (CN) materials. Nanometer-scale multilayered nitride coatings were the first to show the superhard property, and these coatings have quickly made their way into industry as protective coatings for cutting-tool operations. Nanocomposite thin films also exhibit superhardness, and some of these materials have hardnesses approaching that of diamond. Cubic boron nitride (c-BN), which is naturally superhard, has proven very difficult to deposit at thicknesses exceeding $0.1 \mu \mathrm{m}$, but it is now reported that chemical vapor deposition techniques based on fluorine chemistries can produce c-BN films up to $20 \mu \mathrm{m}$ thick. The search to produce cubic $\beta$-CN has led to the development of noncubic, fullerene-like forms of $\mathrm{CN}$ that are both hard and elastic, a very interesting combination of properties that has already been put to use in the harddisk industry. Overall, the development of hard and superhard coatings during the past 20 years has been remarkable. We have progressed from trying (and often failing) to deposit hard coatings to now designing new nanometer-scale multilayered and nanocomposite coatings that exhibit excellent hardness properties and other highperformance characteristics.

Keywords: carbon nitride, cubic boron nitride, nanocomposites, nanometer-scale multilayered coatings, superhard coating materials, superhard oxide materials, thin films.
\end{abstract}

Interest in "superhard" coating materials, defined by hardness values in excess of $40 \mathrm{GPa}$, has increased significantly during the past $10-15$ years. In nature, there are only two materials that qualify as superhard: diamond and cubic boron nitride (c-BN). Diamond is the hardest known material, with a hardness of 70-100 GPa depending on crystallographic orientation and purity; c-BN has a hardness of $50 \mathrm{GPa}$. Many researchers have tried to produce coatings that match or exceed the hardness of these materials. Much of the work has been directed at the deposition of diamond or diamondlike coatings, and there has been much success in this area. In this issue of MRS Bulletin, however, we look at other superhard coating systems that are not carbon-based, with the exception of a review of carbon nitride materials.

In the mid-1980s, researchers at Linköping University ${ }^{1}$ in Sweden showed that it was possible to produce nanometer-scale multilayered coatings of titanium nitride and vanadium nitride with hardness values in excess of $50 \mathrm{GPa}$. Their discovery led to much research activity in this area, and many other nanometer-scale multilayered coatings have been investigated since this initial development. In this issue, we look at two contributions that are directly related to work in this field.

In the first article, Barnett et al. report on efforts to produce high-temperature stability in nanometer-scale multilayered coatings. The superhardness of these materials depends on maintaining a distinct layer structure, which can be destroyed by diffusion at high temperatures. To overcome this problem, Barnett et al. describe the use of immiscible layers to produce superhard coatings that maintain their hardness to temperatures in excess of $1000^{\circ} \mathrm{C}$.

In the second article, Münz et al. look at industrial applications for nanometer-scale multilayered coatings. Much success has been achieved in adapting this technology for use in metal-forming operations. This work represents a rapid transfer of technology from the research stage to the routine use of these coatings in industry.

Related to nanometer-scale multilayered coatings are nanocomposite thin films. Some of these films have hardnesses approaching that of diamond. In his article, Patscheider discusses the effect of nanostructure on coating properties. These films usually have nanocrystalline grains of transition-metal nitrides or carbides surrounded by amorphous hard nitrides. The immiscibility of the amorphous and transition-metal nitrides is key in developing this structure. The amount of the amorphous material and the size and shape of the nanocrystalline grains have a direct influence on the hardness of the material. The hardness enhancement is due to restricted dislocation movement, as it is with nanometer-scale multilayered coatings.

It became apparent very early on that depositing c-BN coatings was difficult. In order to create the cubic phase instead of the hexagonal phase, stress had to be applied to the film. However, this stress caused delamination of the coating once the thickness of the film exceeded a few tenths of a micron. Thick c-BN films have eluded researchers for a long time. In this issue, Zhang et al. report on a method for depositing c-BN films at a thickness in excess of $20 \mu \mathrm{m}$. Their technique uses chemical vapor deposition based on fluorine chemistry. Thick c-BN films will find many useful applications, particularly in metalcutting operations where the hardness and insolubility of c-BN in the work piece will lead to enhanced tool life.

In high-temperature applications, all of the nitride- and carbide-based superhard materials fail due to oxidation. One of the goals in researching new superhard materials has been to develop superhard oxide materials. In his article, Lowther shows how predictive computer modeling is being used to guide researchers in the quest to produce new superhard oxides.

The final article, by Hultman et al., is on resilient fullerene-like carbon nitride coatings. Carbon nitride first came to the notice of most researchers through the published work of Liu and Cohen. ${ }^{2}$ They predicted that the cubic $\beta-C_{3} N_{4}$ form of carbon nitride might be as hard as or harder than diamond. This led to a flurry of attempts to produce this elusive material that continues even today. The guest editors of this issue were among those who have tried to deposit cubic $\beta-C_{3} \mathrm{~N}_{4}$, and like most researchers, they found it difficult to do. However, $\mathrm{CN}_{x}$, where $x$ is around $0.2-0.3$, was found to be a very interesting hard material. It may even be a 
superhard material, but it is not as hard as diamond. Normally, most hard materials are very brittle, but $\mathrm{CN}_{x}$ is very elastic, which seems a contradiction. Hultman et al. show that $\mathrm{CN}_{x}$ has a fullerene-like structure, which gives this material its elastic property. They review the nature of the bonding between the carbon and nitrogen atoms and the issues involved in trying to determine the hardness of the material. The bonding between carbon and nitrogen atoms is key to the degree of elasticity, and this finding is important for the design of tough materials.

Overall, the development of hard and superhard coatings during the past 20 years has been remarkable. We have progressed from trying (and often failing) to deposit hard coatings to now designing new nanometer-scale multilayered and nanocomposite coatings that exhibit excellent hardness properties and other highperformance characteristics. Thick c-BN coatings will quickly find uses in industry, as will hard oxide coatings once they are available, and $\mathrm{CN}_{x}$ has already found industrial acceptance as a protective overcoat on virtually all hard-disk drives manufactured today.

\section{References}

1. U. Helmersson, S. Todorova, S.A. Barnett, J.-E. Sundgren, L.C. Markert, and J.E. Greene, J. Appl. Phys. 62 (1987) p. 481.

2. A.Y. Liu and M.L. Cohen, Phys. Rev. B 41 (1990) p. 10727.
Yip-Wah Chung, Guest Editor of this issue of MRS Bulletin, is a professor of materials science and engineering at Northwestern University in Evanston, Ill. He served as director of the NSF Industry-University Cooperative Research Center for Engineering Tribology at Northwestern from 1987 to 1992 and then as department chair from 1992 to 1998. His research is focused on the physics and chemistry of surfaces and wear-protective coatings. Chung's work on nitrogenated carbon led to its application as a protective overcoating for computer disk drives in use today. He was honored with the Technical Achievement Award from the National Storage Industry Consortium (now the Information Storage Industry Consortium) in 1999 for this contribution. His work on superlattice hard coatings for tribological applications was recognized with the Innovative Research Award given by the Tribology Division of ASME. He is a fellow of AVS and ASM International and a member of the Hong Kong Research Grants Council, which supports basic and applied research in Hong Kong.

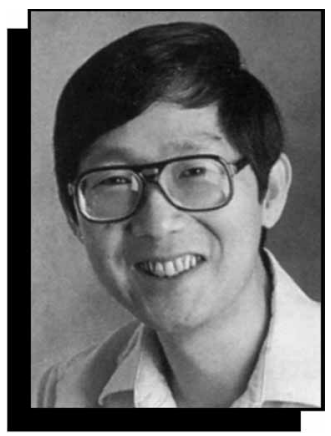

Yip-Wah Chung

Chung can be reached by e-mail at ywchung@ northwestern.edu.

William D. Sproul, Guest Editor of this issue of MRS Bulletin, is a senior scientist in the Power Products business unit at Advanced Energy Industries (AE) in Fort Collins, Col. Prior to AE, he worked at Reactive Sputtering Inc., Sputtered Films Inc., Northwestern University, and Borg-Warner Corp. Throughout his technical career, Sproul has been involved in reactive sputtering of oxide and nitride coatings, and he invented the high-rate reactive sputtering process. He is the author or co-author of over 118 publications and holds 10 U.S. patents. A fellow and past president of the American Vacuum Society, he has chaired the International Conference on Metallurgical

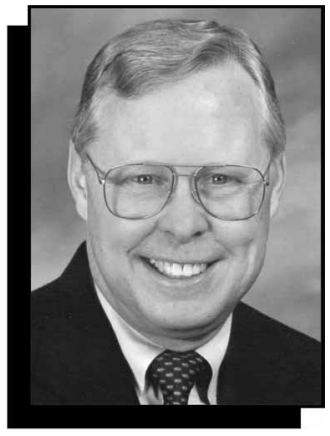

William D. Sproul

Coatings and Thin Films three times. He is a coeditor of Surface and Coatings Technology, and he serves on the editorial board of Vacuum.

Sproul can be reached by e-mail at bill.sproul@ aei.com.

Scott A. Barnett is a professor and associate chair of the Materials Science and Engineering Department at Northwestern University and co-founder of Functional Coating Technology in Evanston, Ill. After receiving his $\mathrm{PhD}$ degree in metallurgy from the University of Illinois at Urbana-Champaign, he held postdoctoral appointments at the University of Illinois and Linköping University (Sweden). His research focuses on colloidal, ionassisted, and physical vapor deposition of semiconductor and ceramic thin films for applications including

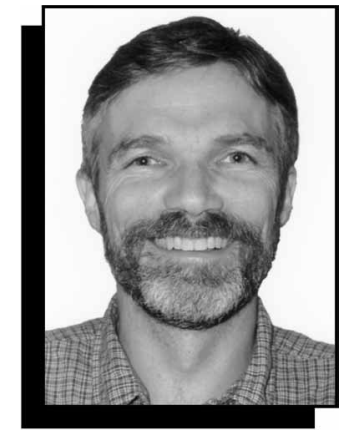

Scott A. Barnett

transparent conductors, hard coatings, and solidoxide fuel cells.

Barnett can be reached by e-mail at s-barnett@ northwestern.edu.

Igor Bello is an associate professor of materials science at City University of Hong Kong and a core member of the Center of SuperDiamond and Advanced Films (COSDAF). After earning his MSEE degree, he received a PhD degree in microelectronics and device fabrication at the Slovak University of Technology, Czechoslovakia. He was an associate professor of microelectronics until 1988 and a vice chairman of the National Expert Assembly for Vacuum Technology and Applications from 1985 to 1988 . Under a Leverhulme Fellowship in 1983-1984, he worked in materials science and implantation processes

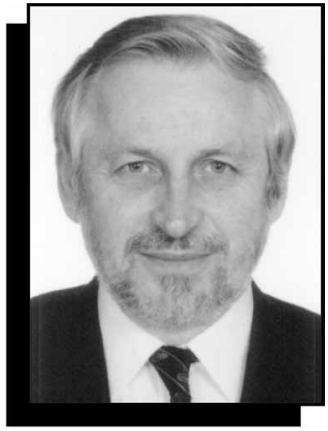

Igor Bello

at the University of Salford, England. He was an adjunct professor, industrial consultant, and research scientist in materials engineering and surface science at the University of Western Ontario, Canada, from 1989 to 1996. Since 1990, he has focused on the synthesis of diamond, diamondlike carbon, and cubic boron nitride and later became involved in the synthesis of nanomaterials. He has published 150 articles in refereed journals, four university textbooks, and 17 industrial reports, and holds six patents.

Bello can be reached by e-mail at apibello@ cityu.edu.hk.

Niklas Hellgren is currently a visiting scientist at the University of Illinois. He received a $\mathrm{PhD}$ degree in materials physics in 1999 from Linköping University in 
Sweden. His research has focused on the materials science and engineering of thin films by vapor phase deposition, in particular, ion-surface interactions, microstructure evolution, and mechanical properties of carbon-based coatings and transition-metal nitrides. He has published some 40 refereed papers and was a recipient of an MRS Graduate Student Award.

Hellgren can be reached by e-mail at hellgren@mrl.uiuc.edu.

Lars Hultman is a professor and head of the Thin-Film Physics Division at Linköping University, Sweden. His research activities focus on the materials physics of thin films by vaporphase deposition, in particular, ion-surface interactions, microstructure evolution, and mechanical properties. His particular interests are in epitaxial film growth, controlled texture and residual stress, and advanced nanostructures for materials such as transition-metal nitrides, Group III nitrides, MAX phases, $\mathrm{SiC}$, and fullerene-like carbon nitride. He received a $\mathrm{PhD}$ degree in materials science in 1988 from Linköping. He has been a visiting scientist at both Northwestern University and the University of Illinois (1989-1990).

Hultman is the leader of a Swedish Strategic Research Foundation Program on LowTemperature Thin-Film Synthesis. He holds research grants from the Swedish Research Council, the EU Commission, and industry. He has published 220 refereed papers and presented 35 invited or plenary talks. In 1994, he was named editor of the journal Vacuum. $\mathrm{He}$ is a board member of the Scandinavian Society for Electron Microscopy, the Swedish Association for Surface Engineering (founding member, 1996-1998), and the Swedish Vacuum Society (president, 1996-1998). He is the chancellor for Sweden to the International Union for Vacuum Science, Technique, and Applications (IUVSTA). In 1990, he was awarded the Welch Scholarship. In 1993, he received the Swedish government award for most prominent young researcher. In 2000, he was honored with the Jacob Wallenberg Foundation Award for Materials Science.

Hultman can be reached by e-mail at larhu@ifm.liu.se.

Ilwon Kim is the chief executive officer of Functional Coating Technology in Evanston, Ill. His current research interests include the fabrication and characterization of nanolayered ultrahard coatings. He is developing nitride/ boride and metal nitride nanolayered coatings for high-temperature wearresistant applications. Kim received his BS degree in metallurgical engineering from Seoul National University, Korea, and his MS degree in physics and $\mathrm{PhD}$ degree in materials science from Northwestern University. His doctoral studies were on the growth and characterization of the structure, high-temperature stability, and mechanical properties of nitride nanolayered coatings

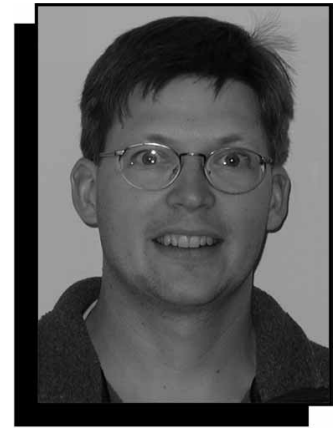

Niklas Hellgren

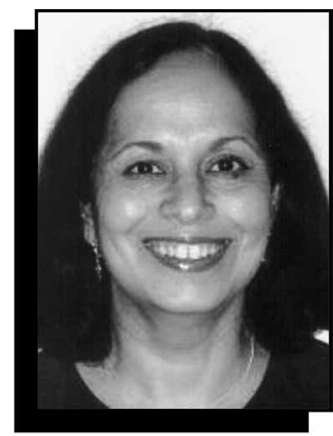

Anita Madan

such as AlN/TiN, AlN/VN, AlN/W, and AlN/NbN. This work focused on the stabilization of the metastable cubic AlN phase in nanolayers and the mechanical properties of the resulting nanolayered coatings.

Kim can be reached by e-mail at ikim@ fctnet.com.

\section{S.T. Lee is a Professor} (Chair) of materials science and director of the Center of SuperDiamond and Advanced Films (COSDAF) at the City University of Hong Kong. His expertise includes diamond and superhard coatings, nanoscale materials, organic LED displays, surface science, and materials characterization.

Lee received his $\mathrm{PhD}$

degree in chemistry from the University of British Columbia in 1974. He joined the City University in 1994

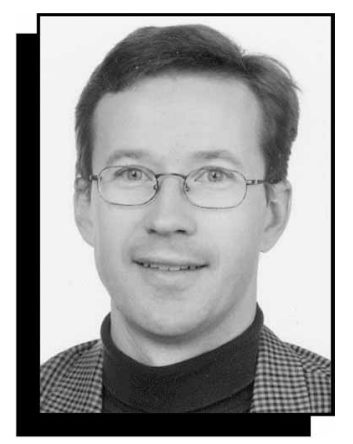

Lars Hultman

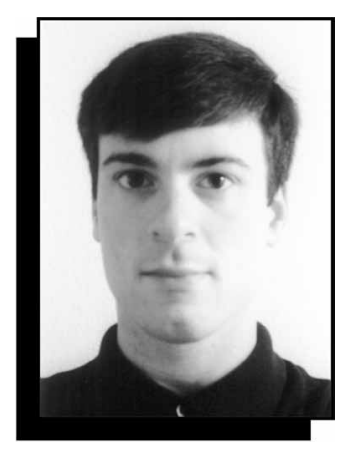

Keith Martin

and was the founding director of COSDAF in 1998.

Lee has filed 17 patents and published three book chapters and more than 300 papers in internationally refereed journals. He received the Humboldt Research Award in 2001 and the Croucher Senior Fellow Award in 2002. He has delivered more than 55 invited talks at international conferences and institutions and is the associate editor of Diamond and Related Materials, a member of the International Advisory Committee for Advanced Functional Materials, and serves on the editorial boards of Applied Physics Letters, the Journal of Applied

Physics, New Carbon

Materials, and the Journal of Nanoscience $\mathcal{E}$

Nanotechnology.

Lee can be reached by e-mail at apannale@ cityu.edu.hk.

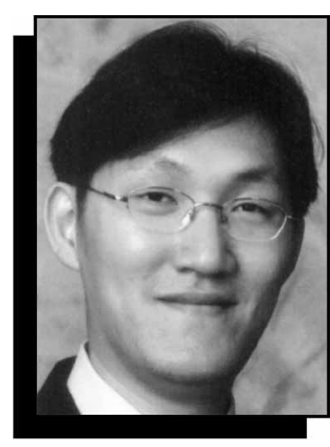

Ilwon Kim

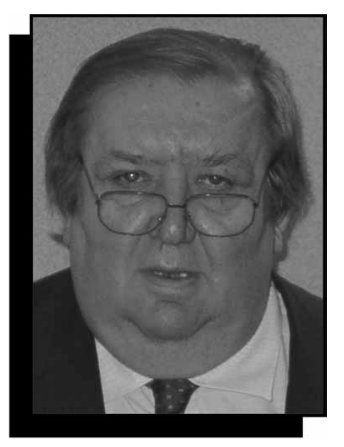

Wolf-Dieter Münz

Yeshayahu (Shay) Lifshitz is a Professor (Chair) of materials science and a core member of the Center of Super-Diamond and Advanced Films (COSDAF) at the City University of Hong Kong. He is currently on leave from Soreq NRC in Israel, where he has worked since 1971 . He received his $\mathrm{PhD}$ degree in physics from the Weizmann Institute, Israel, in 1984. He was a visiting professor at the University of Houston in 1988-1989 (with J.W. Rabalais), where he originated the widely accepted subplantation model of thin-film growth from hyperthermal species. He is the former head of the space technology center at Soreq NRC, established by him in 1991, in parallel with his pioneering work on mass selected ion-beam deposition of carbon. He was 


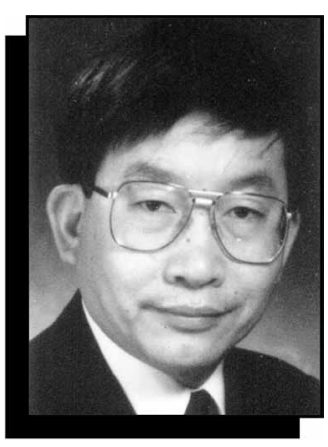

S.T. Lee

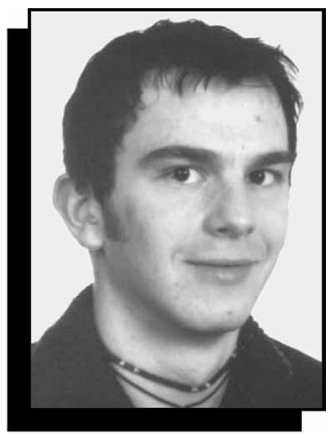

Jörg Neidhardt

an adjunct professor at City University, visiting for short periods of time from 1999 to 2001. He joined the City University faculty in 2001, where he has been working on diamond, cubic boron nitride, and related materials and on nanomaterials. Lifshitz edited a book and has published three book chapters, about 100 papers in refereed journals, and about 150 technical reports. He is a member of the program committees of several diamond- and spacerelated conferences and has delivered numerous invited talks at international conferences and institutions.

Lifshitz can be reached by e-mail at apshay@cityu.edu.hk.

\section{J.E. (Ted) Lowther is a} professor of computational physics at the University of the Witwatersrand in Johan-

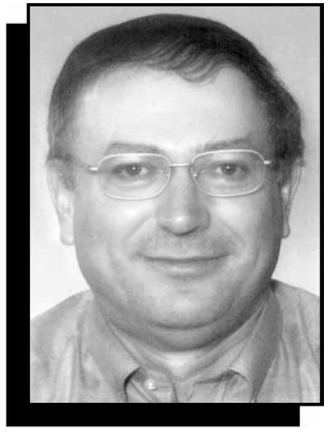

Yeshayahu (Shay) Lifshitz

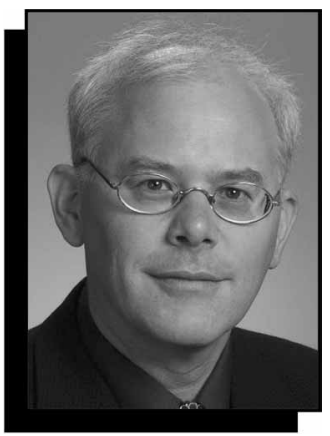

Jörg Patscheider

nesburg, South Africa. Since earning his $\mathrm{PhD}$ degree from Hull University, England, in 1970, he has studied the physics of diamond and related hard materials as well as several aspects of semiconducting materials. He regularly consults with several industries in South Africa, in particular, the Industrial Diamond Division of De Beers. In addition, he is interested in the application of group theory to solids and the crystal field theory of point defects in a variety of materials. He has spent several sabbaticals in industry and at universities, most recently at Texas Tech University (2000), where he worked on nitrogen in gallium arsenide. Currently, he is actively engaged in a continuing search for novel ultrahard ceramics and further understanding of the properties of defects in diamond.

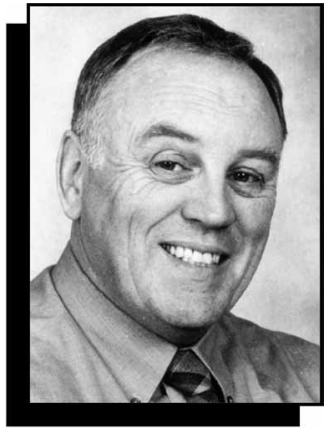

J.E. (Ted) Lowther

Lowther can be reached by e-mail at lowther@physnet.phys. wits.ac.za.

Anita Madan is a research and development scientist in the Microelectronics Division at IBM in Fishkill, N.Y., where she works in the Technology Analysis Group, providing analytical support to the various development programs in the division. She uses x-ray diffraction and reflectometry techniques to address a wide variety of materials issues involving both semiconductors and ceramic chip carriers. Madan received her $\mathrm{PhD}$ degree in physics at Northwestern University. Before joining IBM, she worked at the Advanced Coating Technology Group at Northwestern, developing novel nanolayered coatings for hightemperature applications.

Madan can be reached by e-mail at madaanit@us.ibm.com.

Keith Martin received a $\mathrm{PhD}$ degree in materials science and engineering in 2001 at Northwestern University in Evanston, Ill., where he studied nitride/boride nanolayered hard coatings. After graduation, he worked for Functional
Coating Technology in Evanston, where he was a researcher in the area of integrated solid-oxide fuel cells. He recently joined the Intel Portland Technology Development Group, where he works in the area of 300-mm microprocessor lithography.

Martin can be reached by e-mail at keith.j.martin@intel.com.

Wolf-Dieter Münz is a professor of surface engineering at Sheffield Hallam University in Sheffield, England. He also heads the Surface Engineering Research Group, where he has driven a number of very successful U.K.- and E.C.-funded research programs applying arc bond sputtering technology to a number of hard-coating areas. Among these are coatings tailored for wear resistance, hightemperature oxidation resistance, corrosion resistance, and decorative applications. Münz earned a PhD degree in experimental physics from the University of Graz, Austria. He has had a varied and successful career in PVD microelectronic-circuit technology and all aspects of surface engineering research and development, including optical, tribological, and architectural-glass coatings. In his 28-year industrial career, he has worked for a number of prominent companies, including Siemens, Leybold AG, and Hauzer Techno Coating Europe, where he was general director. Münz received the 2001 IUVSTA Prize in Technology for pioneering advances in vacuumbased material coatings that have found application in a wide range of products.

Münz can be reached by e-mail at d.munz@ shu.ac.uk.

Jörg Neidhardt is pursuing his $\mathrm{PhD}$ degree at the Thin-Film Physics Division within Linköping University in Sweden. His research concerns synthesisstructure-property relationships for fullerenelike carbon nitride coatings made by reactive magnetron sputtering. He holds the degree of diploma engineer in applied physics from the West Saxonian University of Applied Sciences at Zwickau, Germany. In 1999, he was a visiting student at Sheffield Hallam University in England, working with arc-bond sputtering technology of carbon-enriched TiN and TiAlN-based coating systems.

Neidhardt can be reached by e-mail at jorne@ifm.liu.se.

Jörg Patscheider established the thin-film technology laboratory at EMPA (Swiss Federal Laboratories for Materials Testing and Research, Dübendorf) and has been a researcher there since 1991. He carries out applicationoriented R\&D work on thin films of diamond, diamond-like carbon, and nanocomposites with universities and industrial companies; at present, his interests lie in nanostructured coatings. Patscheider received his $\mathrm{PhD}$ degree from the University of Zurich for his work on plasma-assisted chemical vapor deposition of $\mathrm{Al}_{2} \mathrm{O}_{3}$ and TiN; following graduation, he was 


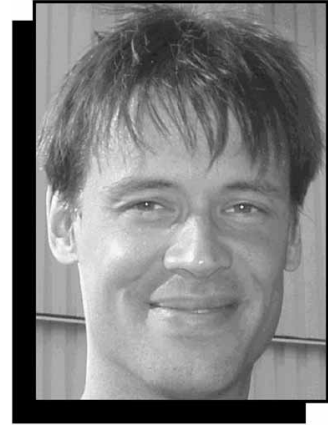

Hans Sjöström

a postdoctoral fellow at Texas A\&M University. In 2002, he was a visiting scientist at the University of Illinois in Urbana-Champaign.

Patscheider can be reached by e-mail at joerg.patscheider@ empa.ch.

Hans Sjöström is a management and technology consultant with Sjöström Coating Consulting in Sweden. He received a $\mathrm{PhD}$ degree in materials science in 1995 from Linköping University. Between 1996 and 2000, he initiated and built the Coated Bearings Division within AB SKF.

Sjöström's research activities focus on the materials science and engineering of thin films by vapor phase deposi-

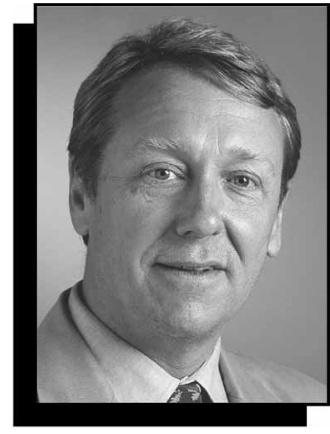

Jan-Eric Sundgren

tion, in particular, microstructure, mechanical properties, and tribology. He has published about 20 refereed papers, holds two patents, and has been awarded the Sandvik Coromant stipend.

Sjöström has specialized in research and development with close connections to market and production. As a consultant, he has supported several international companies in creating more effective development processes as well as coordinating interactions between industry and university.

Sjöström can be reached by e-mail at hans@sjostrom.se.

Jan-Eric Sundgren is president of Chalmers University of Technology

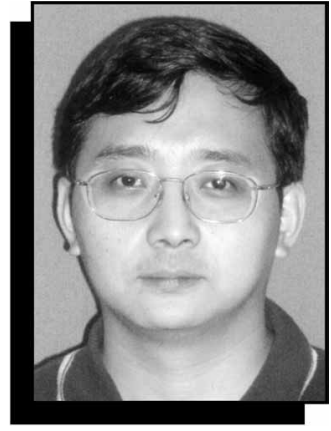

W.J. Zhang

in Göteborg, Sweden, a post he had held since 1998. Before joining Chalmers, he was Secretary General of the Swedish Research Council for engineering sciences (1995-1998) and a full professor of thin-film physics at Linköping University. $\mathrm{He}$ is currently on the board of directors for the Swedish Institute for Measurement and Testing and of Impact Coatings Inc. He is also on the International Advisory Board of the Alliance for Global Sustainability and is a member of the Swedish Royal Academy of Engineering. He has been a visiting professor at the University of Illinois and has served on the board of directors for several Swedish re- search funding agencies as well as on boards for EU framework programs for research.

Sundgren's research has been focused on understanding relationships between process parameters, structure, and properties of thin films grown from the vapor phase. His studies have included both pure-metal and semiconductor films and compound films, such as nitrides and carbides, grown by methods including sputtering and evaporation (molecular-beam epitaxy). He has published more than 300 research papers in refereed journals and given more than 100 invited talks at conferences. In 1984, he received the Jacob Wallenberg Award for work on growth mechanisms and defect structures of hard transition-metal nitride films, and in 1995, he was the first European to be awarded the John Thornton Memorial Award by the American Vacuum Society for seminal contributions to the science and applications of hard coatings, particularly transitionmetal nitrides.
Sundgren can be reached by e-mail at jan-eric.sundgren@ adm.chalmers.se.

W.J. Zhang received his BS, MS, and PhD degrees in physics from Lanzhou University, China. He held a postdoctoral post at the Fraunhofer Institute for Surface Engineering and Thin Films in Germany from 1995 to 1997. He joined the Center of Super-Diamond and Advanced Films (COSDAF) at the City University of Hong Kong as a research fellow in 1997. From 1998 to 2000 , he worked as a Science and Technology Agency fellow at the National Institute for Research in Inorganic Materials (NIRIM) in Japan before rejoining COSDAF as a senior research fellow in 2000. His research interests include diamond and superhard coatings, nanoscale materials, and materials characterization. He is the author or co-author of more than 50 papers in internationally refereed journals and holds three patents.

Zhang can be reached by e-mail at apwjzh@ cityu.edu.hk.

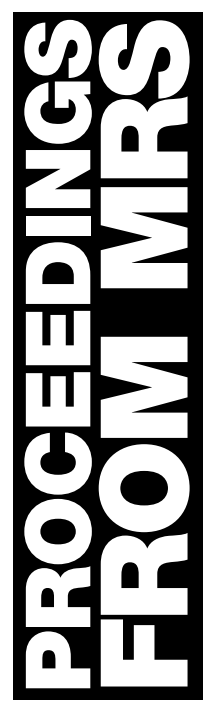

\section{Don't Miss These Publications from the Materials Research Society}

Nanophase and Nanocomposite Materials IV *

Volume 703-B

\$ 81.00 MRS Member

$\$ 93.00$ U.S. List

$\$ 106.00$ Non-U.S

Surface Engineering 2001-Fundamentals and Applications*

Volume 697-B

$\$ 76.00$ MRS Member

$\$ 87.00$ U.S. List

$\$ 100.00$ Non-U.S.
Mechanisms of Surface and Microstructure Evolution in Deposited Films and Film Structures*

Volume 672-B

$\$ 75.00$ MRS Member

$\$ 86.00$ U.S. List

$\$ 98.00$ Non-U.S.

Thin Films-Stresses and Mechanical Properties VIII

Volume 594-B

\$81.00 MRS Member

$\$ 93.00$ U.S. List

$\$ 106.00$ Non-U.S.

For more information, or to order any of the proceedings volumes listed above, contact the MRS Customer Services Department. MRS TEL 724-779-3003 MIRIS FAX 724-779-8313 